\title{
特集 もやもや病
}

\section{もやもや病間接血行再建術における中硬膜動脈の温存方法}

\author{
杉野 寿哉 ${ }^{1}$, 三上 毅 ${ }^{1}$, 飯星 智史 ${ }^{1}$ \\ 寶金 清博 ${ }^{2}$, 三國 信啓 ${ }^{1}$
}

\section{The Preservation of Middle Meningeal Artery in Surgical Revascularization for Moyamoya Disease}

Toshiya Sugino, M.D., ${ }^{1}$ Takeshi Mikami, M.D., ${ }^{1}$ Satoshi Irhoshi, M.D., ${ }^{1}$ Kiyohiro Houkin, M.D., ${ }^{2}$ and Nobuhiro MikunI, M.D. ${ }^{1}$

${ }^{1}$ Department of Neurosurgery, Sapporo Medical University, and ${ }^{2}$ Department of Neurosurgery, Hokkaido University Graduate School of Medicine, Sapporo, Hokkaido, Japan

Summary: We present the preservation of middle meningeal artery (MMA) in surgical revascularization for moyamoya disease. We examined 10 patients with moyamoya disease and performed surgical revascularization. The mean age of the patients was 27.8 years. We presurgically evaluated the three-dimensional (3-D) relationships of MMA and cranial sutures in the pterion by volumetric imaging of 3-D contrast enhanced computed tomography (CT). The 3-D anatomies were visualized by adjusting the window width, window level, and opacity level of the specific CT value for each structure, and the relationship of the MMA and the suture. This visualization was crucial for drilling to perform craniotomies. The MMA from bone to dura is exposed for drilling around the pterion. The preservation of the MMA with this method was achieved in all patients with moyamoya disease.

Presurgical evaluation using volumetric imaging of 3-D CT is a convenient and valuable method for obtaining the anatomic information. The usefulness of the drilling distal to the pterion in patients with moyamoya disease to preserve MMA was confirmed.

\author{
Key words: \\ - middle meningeal artery \\ - moyamoya disease \\ - revascularization \\ - computed tomography
}

Surg Cereb Stroke

(Jpn) 40: 89-93, 2012

\section{はじめに}

もやもや病は，両側性に頭蓋内内䅡動脈終末部，前およ び中大脳動脈近位部に狭窄または閉塞がみられ，その付近 に異常血管網を特徵とする原因不明の疾患である。もやも や病に対する血行再建術として, 浅側頭動脈・中大脳動脈 吻合術(STA-MCA 吻合術)を代表とする直接血行再建術
と encephalo-myo-synangiosis (EMS), encephalo-arteriosynangiosis (EAS), encephalo-duro-synangiosis (EDS) や それらの組み合わせを用いた間接血行再建術が用いられ る. 間接的血行再建術は側頭筋，硬膜などの組織と脳表と の間に血管新生が生じることにより大脳への血流が新生さ れることを期待する術式である。 そのため手術に際して は，側頭筋を栄養する深側頭動脈や硬膜を栄養する中硬膜

\footnotetext{
${ }^{1}$ 札幌医科大学医学部 脳神経外科, ${ }^{2}$ 北海道大学大学院医学研究科 脳神経外科(受稿日 2011.12.22)(脱稿日 2012.1.10)〔連絡先： T060-8543 北海道札幌市中央区南 1 条西 16 丁目 札幌医科大学医学部 脳神経外科 杉野寿哉] [Address correspondence: Toshiya Sugino, M.D., Department of Neurosurgery, Sapporo Medical University, South 1 West 16, Chuo-ku, Sapporo, Hokkaido 060-8543, Japan]
} 


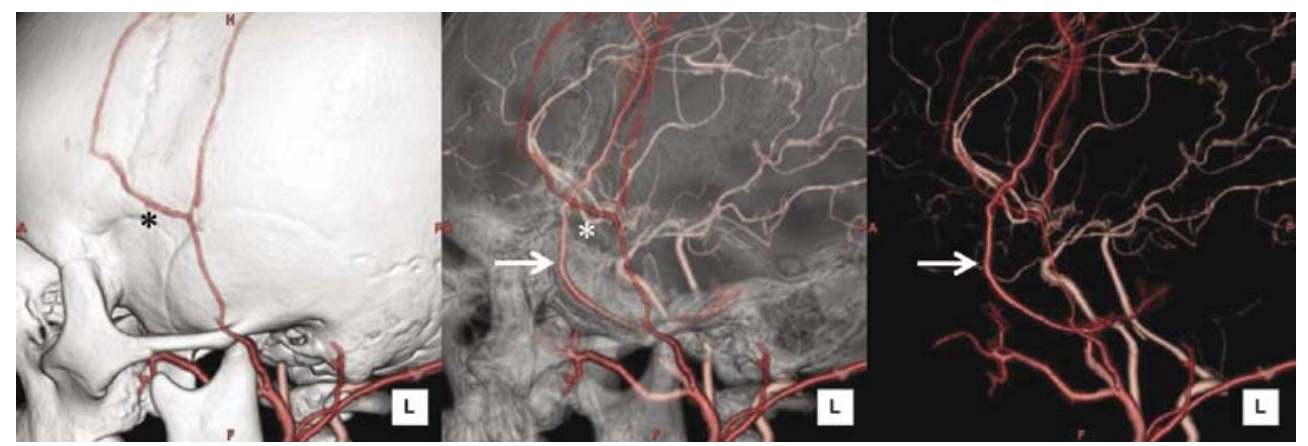

Fig. 1 A process of presurgical evaluation using volumetric imaging of three-dimensional contrast enhanced computed tomography in a patient with moyamoya disease.

A: By operating the window level and window width of the CT value, STA and the pterion $\left({ }^{*}\right)$ are revealed.

B: Operating the opacity level of the cranium, the relationship between the MMA (arrow) and the pterion $\left({ }^{*}\right)$ is visualized through the translucent cranium surface. C: Operating the opacity level of the cranium, the relationship between the STA and the MCA of donor is visualized through the translucent cranium surface.

動脈を損傷しないような工夫が必要である.

われわれの施設では，小児例㧍よび成人例のもやもや病 に対して基本的に直接血行再建術を行い，さらに間接血行 再建として中硬膜動脈の温存を重視している. 当施設にお ける中硬膜動脈の温存方法を紹介するとともにその意義に ついて検討した.

\section{対 象}

2009 年 9 月から 2011 年 3 月までに札幌医科大学付属病 院で, もやもや病に対し血行再建術を施行した 10 症例を 対象とした. 年齢は 4-49 歳 (平均 27.8 歳), 男性 5例, 女 性 5 例であった. 15 歳未満の小児例が 4 例, 15 歳以上の 成人例が 6 例であった. 全例症候性であり, その発症様式 は TIA が 8 例, 脳梗塞が 1 例, 脳出血が 1 例であった。

\section{方法}

\section{1. 術前評価}

CT 撮像には札幌医科大学付属病院の Light speed $\mathrm{VCT}$ (GE 横河メディカルシステム)を使用し, 造影剤 Iopamidol (Iopamiron 300)を bolus tracking 法により 1-1.2 $\mathrm{mL} / \mathrm{kg}$ 静脈注射し, その後スライス厚 $0.625 \mathrm{~mm} に$ て撮像した. 画像データを 3 次元画像解析ソフトゥェア (ZIOstation system 1000;アミン株式会社)で画像解析を 行った. 撮像デー夕を volume renderingによって再構成 を行い, 骨, 造影血管に相当する CT 值付近の window level と window widthをそれぞれ調節することで, 骨, 血管の可視化を行った. また opacity level の調節により， 骨を透過させ, 頭蓋骨縫合線と中硬膜動脈の位置関係を把 握した (Fig. 1)。

\section{2. 手術法}

皮虐切開をおき，浅側頭動脈を剥離したのち，骨膜およ び側頭筋を頭蓋骨より剝離し, 頭蓋骨を露出する. 3DCT と実際の術野を照らし合わせることにより, 縫合線から pterion 付近で中硬膜動脈の部位を推定する. 中硬膜動脈 は pterionより遠位側にいくほど，板間内を走行するより も硬膜上を走行するようになるため, 骨削除範囲は遠位側 を頂点とした三角形にするのがよいと考えている(Fig. 2A). 推定した中硬膜動脈の部位で, 外板を $6 \mathrm{~mm}$ のス チールバーを用いて骨切除を行う。板間から内板にかけて は $4 \mathrm{~mm}$ のダイヤモンドバーを用いて顕微鏡下に骨切除 を行ったほうが安全である。骨切除範囲内で中硬膜動脈が 板間内を走行している場合には遠位側に骨切除を行い, 必 ず硬膜上を走行する部位を確認するまで骨切除を行う(Fig. 2B). 中硬膜動脈にはより太い中硬膜静脈が伴走しており, 骨切除の際中硬膜静脈を損傷しないように注意する。骨を 薄くなるまで削り，一部硬膜が露出されれば硬膜より薄く なった骨を剝離しケリソンパンチなどを用いて骨除去を行 う. Fig. 2B のごとく burr holeを作成し, 骨切除した部 位を起点として開頭を行っている. 直接血行再建として, STA-MCA 吻合術を施行し, 間接血行再建術として EDMS およびEDASを施行した. 中硬膜動脈の開通は, 術中 ICG (Fig. 2D) と術後急性期(翌日〜 1 週間前)の MRA, CTA で評価した.

\section{結果}

\section{術中評価}

小児例および成人例のもやもや病全例に対して, STAMCA 吻合術に加え, EDMS およびEDASを施行した。 


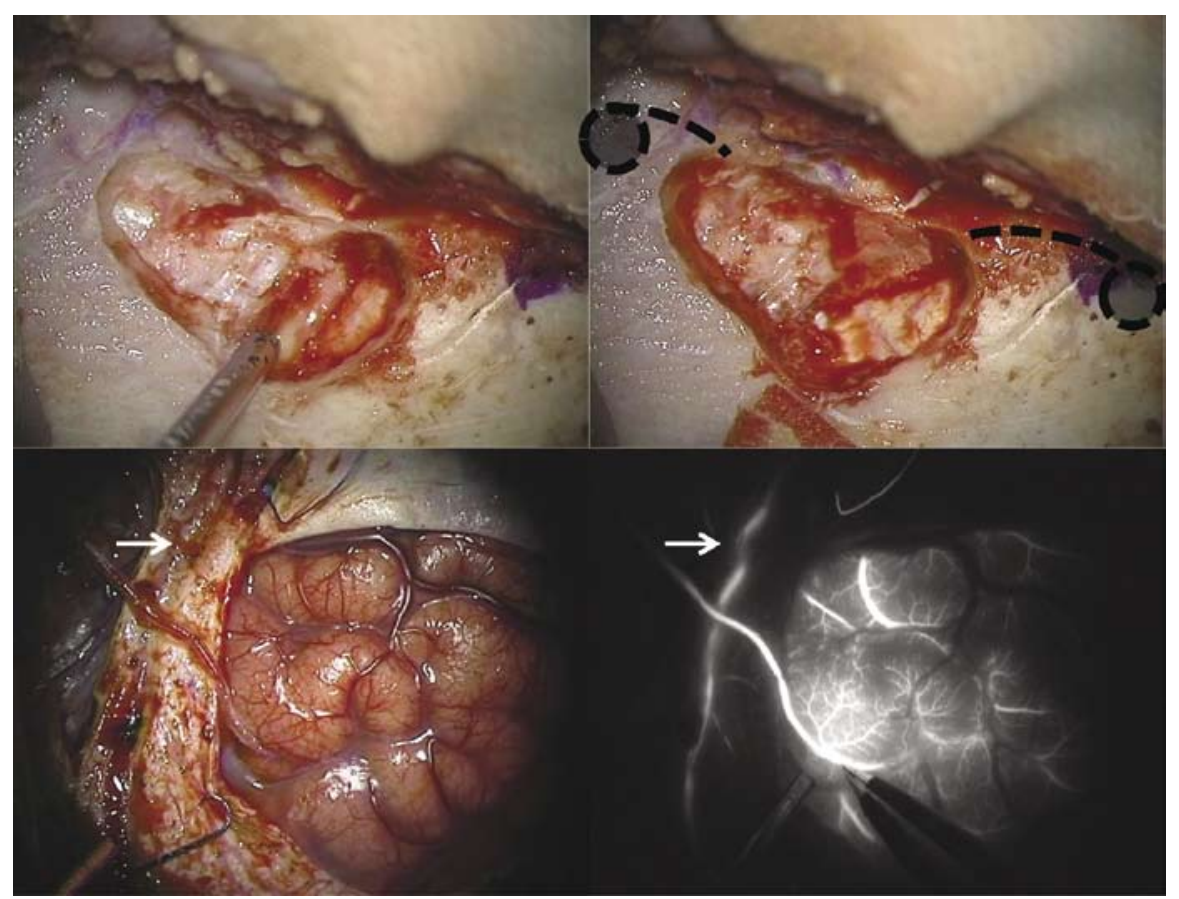

Fig. 2 The illustrative photos in a patients undergoing left STA-MCA bypass and EDAS.

A: The range of drilling bone made around the pterion.

B: The range of drilling bone was appropriate for the craniectomy with preserving MMA (arrow).

C: The MMA (arrow), STA-MCA bypass are intraoperatively confirmed.

D: Intraoperative ICG videography confirmed the patency of the MMA (arrow) and bypass graft.

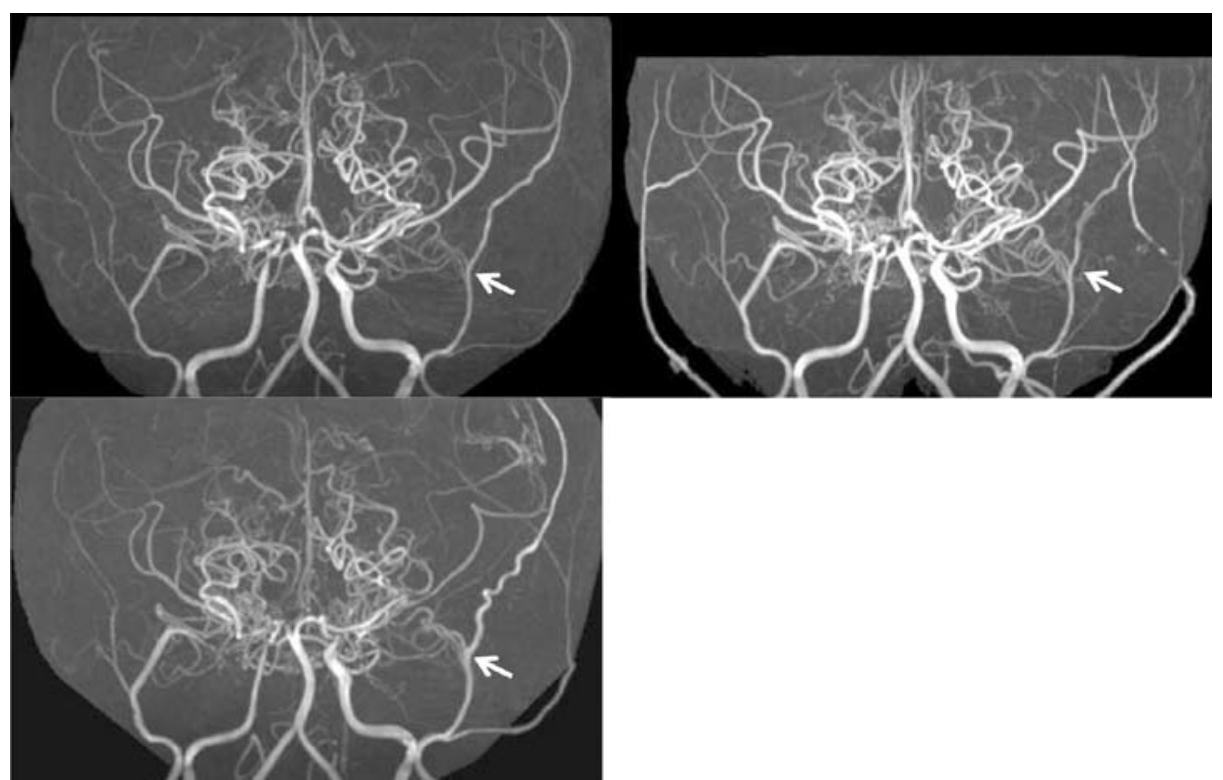

Fig. 3 A: Two-dimensional (2D) time of flight (TOF) magnetic resonance (MR) angiogram obtained before the operation.

B: 2D TOF MR angiogram obtained on postopetative one day demonstrating the middle meningeal artery (arrow).

C: 2D TOF MR angiogram obtained on postopetative six months demonstrating higher intensity of the middle meningeal artery (arrow) compared to before the operation. 
この方法により, 解剖学的に中硬膜動脈を全例温存するこ とができ, ICGでも中硬膜動脈の開通を全例で確認するこ とができた。また術後急性期の頭部 MRA, CTAで, 中 硬膜動脈の開存を全例確認することができた.

\section{症例提示}

繰り返す右上下肢の脱力発作のため当科紹介となった 4 歳男児. 頭部 MRI では左側頭葉から頭頂葉, 両側分水嶺 領域に脳梗塞を認め, 頭部 MRA では両側内澒動脈終末部, 前および中大脳動脈近位部に狭乍性変化と, 両側大脳基底 核部に異常血管網を認めたため(Fig. 3A)，もやもや病と 診断した.

安静時 SPECT では左大脳半球の血流低下を認め, 右上 下肢の脱力発作が頻発していたため, 左側の血行再建術を 予定した。術前に撮影した造影 CT のデータを用い, 術前 に頭蓋骨縫合線と中硬膜動脈の位置関係を評価した(Fig. 1). 実際の術野で，術前の 3DCT と照らし合わせること により, 縫合線から中硬膜動脈の部位を推定し, 骨削除範 囲は決定した（Fig. 2A）。ドリルを用いて骨切除を行い， 中硬膜動脈が硬膜上を走行することを確認，図のごとく burr holeを作成し，骨切除した部位を起点とした開頭を 行った(Fig. 2B). 血行再建として, STA-MCA 吻合術, EDASを施行し (Fig. 2C), 術中 ICGで bypass と中硬膜 動脈の開通を確認した(Fig. 2D). 術翌日の頭部 MRA で 中硬膜動脈の開存を確認し(Fig. 3B), 術後 6 力月の頭部 MRA では, 術前に比べ, 左中硬膜動脈の発達が認められ た(Fig. 3C).

\section{考察}

中硬膜動脈は，顎動脈から分岐し，棘孔を通り，中頭蓋 窩に入り anterior branch, petrosal branch, posterior branch に分かれる. 開頭の際に問題になるのは anterior branch であり, 頭蓋内に入ったのち, 側頭骨内面で中硬 膜動脈溝 (groove of middle meningeal artery)を走行する. もやもや病の開頭は, 間接血行再建において重要なドナー である中硬膜動脈の温存を行う必要がある。中硬膜動脈を 温存するためには, 中硬膜動脈が硬膜上を走行する部位を 確保する必要がある，通常，この部位は pterionより遠位 であるため, このレベルでバーホールを拉き, その直下で 中硬膜動脈を確認するのが安全といわれてきた. しかし， この中硬膜動脈溝の深さと距離は, 個人差が大きく, 長い 距離にわたって側頭骨内に動脈溝を形成したり, 深い動脈 溝を形成したり，また実質的に中硬膜動脈が骨板間内を走 行している場合がある。本シリーズにおいても, pterion レベルでは頭蓋骨の厚さ半分を超えるほどの深い溝を形成 していた症例や中硬膜動脈が骨板間内を走行している症例
が存在した。このような場合には, pterionより遠位で中 硬膜動脈の走行を想定した部分にバーホールをおいた時点 で損傷してしまう可能性があり，中硬膜動脈を温存できな いことがある，われわれの方法では，顕微鏡下にドリルで 骨切除することにより, 中硬膜動脈が板間から硬膜に至る 部位を確認することができるため, 中硬膜動脈の温存に有 用であると考えられる。

もやもや病に対する直接または間接血行再建術は, 脳循 環代謝の改善に伴う虚血発作の改善, 脳梗塞のリスク軽 減, 術後 ADL の改善, 長期的高次脑機能予後の改善が報 告されている(1)35-9)1112). 小児もやもや病に対して, STAMCA bypass と EDAMS を施行すると, 術後 3 カ月では 中硬膜動脈の発達が認められ ${ }^{2)}$, 成人もやもや病に対して 間接血行再建術を施行しても, 約 $50 \%$ の症例だが側副血 行路の発達を認めると報告されておりり10)，開頭時の中硬 膜動脈の温存は，間接血行再建術において重要と考えられ る.

\section{結 語}

造影 CT を用いて，骨を透過させ，中硬膜動脈を分別す ることにより，中硬膜動脈，縫合線の位置を術前評価する ことができた。中硬膜動脈の頭蓋骨貫通部を最初に顕微鏡 下にドリルで骨切除することにより，中硬膜動脈の温存が 可能であり，間接血行再建術において有用な方法と考えら れた.

\section{文献}

1) Choi JU, Kim DS, Kim EY, et al: Natural history of moyamoya disease: Comparison of activity of daily living in surgery and non surgery groups. Clin Neurol Neurosurg 99 Suppl 2: S11-S18, 1997

2) Houkin K, Nakayama N, Kuroda S, et al: How does angiogenesis develop in pediatric moyamoya disease after surgery? A prospective study with MR angiography. Childs Nerv Syst 20: 734-741, 2004

3) Houkin K, Kuroda S, Nakayama N: Cerebral revascularization for moyamoya disease in children. Neurosurg Clin N Am 12: 575-584, 2001

4) Houkin K, Kamiyama H, Abe H, et al: Surgical therapy for adult moyamoya disease. Can surgical revascularization prevent the recurrence of intracerebral hemorrhage? Stroke 27: 1342-1346, 1996

5) Ikezaki K, Matsushima T, Kuwabara Y, et al: Cerebral circulation and oxygen metabolism in childhood moyamoya disease: a perioperative positron emission tomography study. $J$ Neurosurg 81: 843-850, 1994

6) Kawaguchi T, Fujita S, Hosoda K, et al: Multiple burrhole operation for adult moyamoya disease. J Neurosurg 84: 468-476, 1996

7) Kuroda S, Houkin K, Kamiyama H, et al: Regional cerebral hemodynamics in childhood moyamoya disease. Child Nerv Syst 11: 584-590, 1995 
8）松島善治, 青柳 傑, 成相 直, ほか：小児もやもや秒患 者の Wechsler 知能テストによる長期知能予後 encephaloduro-arterio-synangiosis 施行後 10 年以上経過した患者の検 討. 小児の脳神経 21: 232-238, 1996

9）宮本 亨, 永田 泉, 唐澤 淳, ほか：もやもや病に対す る直接バイパスの長期予後. 脳卒中の外科 28: 111-114, 2000

10) Mizoi K, Kayama $\mathrm{T}$, Yoshimoto $\mathrm{T}$, et al: Indirect revascularization for moyamoya disease: Is there a benefit effect for adult patients? Surg Neurol 45: 541-549, 1996

11) Morimoto $M$, Iwama $T$, Hashimoto $N$, et al: Efficacy of direct revascularization in adult Moyamoya disease: haemodynamic evaluation by positron emission tomography. Acta Neurochir (Wien) 141: 377-384, 1999

12) Scott RM, Smith JL, Robertson RL, et al: Long-term outcome in children with moyamoya syndrome after cranial revascularization by pial synangiosis. J Neurosurg 100 (2 Suppl Pediatrics): 142-149, 2004 